\title{
The Antecedents of Effectiveness Interactive Advertising in the Social Media
}

\author{
Wei Jia Tan ${ }^{1}$, Choon Ling Kwek ${ }^{1} \&$ Zhongwei $\mathrm{Li}^{1}$ \\ ${ }^{1}$ Faculty of Business and Information Science, UCSI University, Kuala Lumpur, Malaysia \\ Correspondence: Choon Ling Kwek, Faculty of Business and Information Science, UCSI University, No 1, Jalan \\ Menara Gading, UCSI Heights, 56000 Cheras, Kuala Lumpur, Malaysia. Tel: 60-16-688-6248, E-mail: \\ kwekcl@ucsi.edu.my
}

Received: October 12, 2012

Accepted: January 17, $2013 \quad$ Online Published: January 25, 2013

doi:10.5539/ibr.v6n3p88

URL: http://dx.doi.org/10.5539/ibr.v6n3p88

\begin{abstract}
The aim of this article is to find out the effectiveness of the interactive advertising in the contact of social media and also the attitude of consumer towards the interactive advertising. A descriptive research was conducted to address the research objective. The survey research was undertaken among the tertiary students (majoring in mass communication with multimedia background, batch January to April 2012) who study in one of the private universities in Kuala Lumpur, Malaysia. The adopted sampling method was convenience sampling. There were 149 usable questionnaires which were analysed with the Statistical Package for Social Science Software version 17. The study found out that the advertising effectiveness of traditional and interactive advertising should be measured in a different way, or in another word, part of the traditional measures could be used, but the new measures should be add-on. Since the inherent limitation of the cross sectional method, it is suggested to increase the sampling selection and adoption of other factors for the future research.
\end{abstract}

Keywords: effectiveness of interactive advertising, attitude toward advertising, attitude toward advertised brand, purchase intention, time of exposure to advertisement

\section{Introduction}

For more than a decade, the advancement of information and communication technologies has made the interaction between customer and advertiser to be more easier and faster (Pavlou \& Steward, 2000; Lavrakas, 2010). The trend of advertising has changed together with the growth of information and communication technologies throughout the centuries, from the red-and-white striped pole, to the "sandwich men", to television (Petley, 2002). With the emerging of the World Wide Web (Web), social media has stood up and become a platform for a new form of interactive advertising (Li, 2011; Liu, 2003). Studies found out that there is a growing trend in the interactive advertising industry; and the marketer, academicians, and professionals are paying close attention to the effectiveness of interactive advertising (Yang, 1996; Digital Direction, 2011; Peltier, Schibrowsky \& Schultz, 2003).

Many advertisers are using different types of interactive technology to introduce and broadcast their offerings, and it is the time where the effectiveness of Internet advertising needs to be measured (Pavlou \& Stewart, 2000; Lavrakas, 2010). Thus, the measurement of the advertising effectiveness that used in the traditional advertising might or might not be useful to measure the 'new advertising' (ie., interactive advertising) (Li \& Leckenby, 2004; Pavlou \& Stewart, 2000; Yang, 1996; Dreze \& Zufrydn, 1998). To gather more understanding on the effectiveness of interactive advertising, the study will first start off with the literature review of integrated marketing communication (IMC), followed by advertising, interactive advertising, interactivity, and lastly the determinants of the effectiveness of interactive advertising.

\section{Literature Review}

\subsection{Integrated Marketing Communication (IMC)}

According to Kitchen and Burgmann (2010), although the first publication of Integrated Marketing Communication (IMC) was done by Schultz, Tannenbaum, and Lauterborn in 1993; but yet the study was first conducted by Caywood, Schultz, and Wang at the end of the 1980s, and gained widespread of attention and interest among the academics and practitioners worldwide (Kliatchko, 2005). Back in the 1980s, the concept of 
IMC was unrecognized, embryonic, and emergent, which many see each promotional tool as separate and distinct, and this phenomenon had driven into the 1990s (Kitchen \& Pelsmacker, 2004; Kitchen, Brignell, Li \& Jones, 2004).

In the early 1997, IMC development had turned most clients and agencies away from singular element of the promotional mix and was seen as the 'way forward' (Kitchen \& Pelsmacker, 2004). The advertising agencies which were led by the American Association of Advertising Agencies had tried to name this concept as the 'new advertising', 'relationship marketing', 'integrated marketing', 'integrated communications', and so on (Thorson \& Moore, 1996; Kliatchko, as cited in Kliatchko, 2005), but regardless of the name given to the IMC, this new approach had brought an irreversible prevailing tendency among academic and industry practitioners to the business and marketing communications planning (Kliatchko, 2005). Thus, IMC is never a new concept and was more than a fad (Thorson \& Moore, 1996).

In the last decade of 20th century, IMC is the major communications development and many had proclaimed it to be the key competitive advantage of marketing because IMC helps to increase communications impact, create more effective and creative ideas, provide greater communication reliability, and improve the client return on communication investment (Kitchen \& Pelsmacker, 2004). Kitchen and Burgmann (2010) further explain that by using IMC, it does not reflect that organization should only work with one message, but rather, an integrated approach could provide encouragement of working under multiple targets and achieve integration of different brands, communication messages, and functions within one company. Furthermore, Chitty, Barker, Valos and Shimp (2011) feel that IMC is about delivering relevant brand messages to the target customers, with the aim of direct influence of buying behaviour and building profitable relationship with various forms of marcom. Through the IMC, the marketplace has shift away from the traditional focus on mass communication, and firms from the business and communication industry agree that IMC plays an important part to their work (Stanaland, Webster \& Taylor, 2009).

According to Kitchen and Burgmann (2010), delivering messages to consumers by using available promotional mix elements is one of the key for successful organizations during the mid-20th century. In the late-20th and early 21 st century, there are getting more multiplication of media channels, hence, the integration and coordination of different messages in portraying a single and unique image to the public has turn out to be more important and difficult to achieve. Producing greater results through IMC by using multiple communication tools is strongly suggested by Shimp (2010). With the advancement of information and communications technology, the concept of interactive advertising as parts of the IMC has getting closely monitored and evaluated by the academicians and practitioners because Duncan $(2005$, p. 1) mentions that "IMC is an ongoing, interactive process" and interactive in the mode of "two-way communication". Thus, the following content will critically evaluate the concepts of interactivity and interactive advertising in detail.

\subsection{Interactivity}

Raman and Leckenby (as cited in Yang, 1996, p.3) refer interactivity as the interaction between senders (advertiser) and receivers (customer) in the communication process. Karimova (2011, p.1) argues that interactivity is an important element for all types of advertising regardless of traditional or 'new media' such as Internet. Shrum, Lowrey and Liu (2009) further argue that interactivity is a structural characteristic or perception that embedded in the different entities in which the interactivity by itself is a multi-dimensional construct. Two-way communication and control are often used as the sub-dimensions of interactivity (Liu, 2003). Two-way communication means the information flows between both parties. With this dimension, it has distinguished the Internet advertising from traditional mass media, as traditional way could only present one way communication from advertiser to the audience (Shrum, Lowrey, \& Liu, 2009).

Interactivity can be taken place between human-human, human-message, and human-machine (Liu \& Shrum, 2002). The first dyad refers to interpersonal communication perspective, such as word-of-mouth. The second dyad refers to the traditional advertising where advertisers deliver messages to the consumers. The last dyad refers to the interaction of consumers with the technology and technical aspect of medium.

According to Shrum, Lowrey and Liu (2009), the interactivity nature of advertising is created via Internet media. In contrasting to the traditional mass media, interactive media (online media) allows the consumers to engage in the advertising process by selecting the preferred information and building two-way communication with advertisers. Besides, Pavlou and Steward (2000) mention that interactivity is not the characteristic of the medium, but yet the characteristic of the consumer. Hence, what make it new are the speed, scope, and scale of interactivity that provided by the latest information and communication technologies. 


\subsection{Interactive Advertising}

Interactive Advertising Bureau (IAB) (n.d.) defines interactive advertising as "all forms of online, wireless and interactive television advertising, including banners, sponsorships, e-mail, keyword searches, referrals, slotting fees, classified ads and interactive television commercials" (Interactive Advertising Bureau, 2012, p. 14). Based on the Digital Direction (2011) statement, digital advertising is part of the interactive advertising. Digital advertising consists of four major categories (Digital direction, 2011):

1) Internet advertising - consists of various types of messages online, including paid search, display ads, video ads, classifieds, and sponsorships.

2) Mobile advertising - this type of advertising involves the delivery of promotional messages through wireless devices, mainly mobile phone and PDAS, in the forms of text messages (SMS), mobile media messaging (MMS), video and television through mobile devices, advertising within the downloadable application, and mobile web.

3) Digital outdoor advertising - includes digital bill boards, interactive 3D displays, and captive video networks, which mainly used in places like malls, clubs, office buildings, roads and so on.

4) In-game advertising - this type of advertising refers to promotional messages in which delivered through computer and video games.

Karimova (2011) argues that the concept of 'interactive' advertising is commonly adopted in the advertising business because the power of new interactive media in easing the transmission of advertising messages. Cutler (as cited in Pavlou \& Stewart, 2000) argues that the new interactive media can serve as a platform to provide rapidly advertise, complete a sale, and collect payment. Hence, the internet, mobile devices, and interactive kiosk are considered as interactive mediums that provide possibility of interactive communication with messages. There are four major components in the interactive media, including two way communication system, the response control in the communication process, the communication relationship and the adoption of database technology (Peltier, Schibrowsky \& Schultz, 2003).

With the increasing popularity of interactive media, advertiser and marketing professional are paying more attention to the interactive advertising and the use of interactive media (Yang, 1996; Digital Direction, 2011; Peltier, Schibrowsky \& Schultz, 2003). Based on IAB Internet Advertising Revenue Report 2008, it mentions that digital video advertising is one of the fastest growing segments of interactive advertising (Brown \& Logic, 2008). In addition, the President and CEO of the IAB, Randall Rothenberg mentions that there is an on-going secular shift from traditional media to online media because the marketers had recognized the effectiveness of interactive advertising in influencing consumers and delivering measurable results (IAB, 2009).

With the establishment of the National Information Infrastructure (NII) and the Global Information Infrastructure (GII), the popularity of Internet throughout the wired globe has turned interactive advertising globally. Therefore, the global users can simply get-in-touch with the interactive advertising on Internet via relevant computer hardware and software (Yang, 1996).

In the past, the traditional advertising was an approach to the consumers, but interactive advertising indicates how consumers deal with the advertising (Pavlou \& Steward, 2000). According to Yang (1996), the differences between the traditional advertising and interactive advertising are that the consumer can choose the desired and the need of advertising information that presented to them. In addition, interactive advertising could also help to increase the consumer's decisions making process, customers' involvement, customers' satisfaction and customer's trust toward the information delivered by the interactive media (Pavlou \& Steward, 2000).

Despite of the above advantages of using interactive advertising, an understanding towards the effects of interactive advertising and designing appropriate measurements to evaluate the advertising effectiveness in an interactive context are crucial (Palvou \& Steward, 2000). According to Li and Leckenby (2004), the issue of internet advertising had become part of the question about the effectiveness of interactive advertising, and it should be examined in a similar fashion as traditional advertising. Consequently, the following content will evaluate the effectiveness of interactive advertising and its associated determinants.

\subsection{Effectiveness of Interactive Advertising}

Li and Leckenby (2004) argue that regardless of the medium or message characteristics, the effectiveness of interactive advertising should be judged in the perspective of an overall philosophy model of advertising effectiveness. Pavlou and Stewart (2000) mention that both traditional and interactive advertising have the same objectives of advertising, and hence the effectiveness of both would remain relevant. Furthermore, Yang (1996) 
asserts that if there are no significant effects of interactivity on advertising effectiveness based on the traditional measures, it may attribute to the invalidity of traditional measures. Hence, new measures are needed in order to better fit the new advertising environment (Yang, 1997). In the study of Yang (1996), four measures were used to evaluate the effectiveness of advertising: (1) attitude towards advertising (Aad); (2) attitude towards the advertised brand $(\mathrm{Ab}) ;(3)$ purchase intention; and (4) time of exposure to advertisements.

However, there is another school of thought in the literature argues that the effectiveness of internet advertising should not be compared in mirroring to the traditional advertising. Third party companies, such as Netcount and I/PRO, propose a series of web-specific measures such as click-through rates, ad transfers, reach and frequency to measure the effectiveness on Web in comparing with the standard media (Dreze \& Zufrydn, 1998). Dreze and Zufryden (1998) use reach, frequency, and gross rating points (GRP) to measure the effectiveness of interactive advertising. The world global marketing and advertising research company, Nielsen, measures the online advertising effectiveness by using the brand favourability, message equity, brand consideration, purchase propensity, the effectiveness of creative execution, place impact, and frequency of exposure (The Nielson Company, 2009).

In 2008, the Interactive Advertising Bureau (IAB) has conducted a study of the predominant methodologies to test the effectiveness of Internet advertising (Lavrakas, 2010). Even though there is no outcome mentioned in Lavrakas study, but the variables that used in the questionnaire to measure the effectiveness of internet advertisements are as below (Lavrakas, 2010):

1) Dependent Variables - brand awareness; brand exposure; brand image; future propensity to purchase brand; and actual brand purchases.

2) Independent Variables - demographics; lifestyle and other psychographics (Internet usage per week, use of a shared or non-shared computer; past purchasing behaviour; other attitudes about the domain of products or services into which the brand falls).

On top of that, Lavrakas $(2010$, p. 27) also provides a few variables that could be added in testing the effectiveness of internet advertising as below:

1) Dependent variables - purchase intention; trust in the brand; site visit experience; and interactivity.

2) Independent variables - the number of times a consumer surfed the website in which the advertising campaign is being conducted; how many time a person delete cookies on the computer; ethnicity; educational attainment; home renter status; presence of non-adult children in the home.

According to Pavlou and Stewart (2000), there are two types of measurement for the effectiveness of advertising. The first type of measurement primarily focuses on the media choice, information search, and information processing. Whereas the second type of measurement is focusing on the effects of consumer in using interactive media, such as brand awareness, product recall, attitude towards the product, and product choice. For the purpose of evaluating the effectiveness of interactive advertising in the perspective of social media, this study will look into the measures towards the effectiveness of interactive advertising that proposed by Yang (1996) as below.

\subsubsection{Attitude toward Advertising (Aad)}

Kotler and Keller (2006) describe an attitude as a person that endures the favourability evaluations, emotional feelings, and action tendencies toward some objects or ideas. MacKenzie and Lutz (1989) define attitude toward advertising (Aad) as the tendency to reply in either a favourable or unfavourable manner towards a specific advertising during the exposure. The positive Aad is referred to the favourable evaluation and the consumer willingness towards the advertisement, or in another word, the consumer is more likely to be persuaded by the advertisement (Saadeghvaziri \& Seyedjavadain, 2011; Hwang, Yoon \& Park, 2011).

Over the last few decades, Aad has always been studied whenever it links to advertising as it has been considered as an efficient indicator for measuring the effectiveness of advertising (Yoo, Kim \& Stout, 2004) and the impact of Aad on the advertising effectiveness is significant (Mehta \& Purvis, 1995).

Saadeghvaziri and Seyedjavadain (2011) mention that the respondents' Aad will be different due to different cultural background. There are studies show that the respondents from Eastern (Chinese) and the Middle Eastern (Iranians) held positive attitudes toward interactive advertising, whereas the Western (Americans) is in an opposite way (Ferle \& Lee, 2008; Saadeghvaziri \& Seyedjavadain, 2011).

Wang (2011) mentions that interactive ads tend to generate stronger Aad as comparing to the traditional ads but Yang (1996) mentions that one's Aad is not contributed by the interactive advertising. If that person is lack of interest in shopping the virtual stores, he/she would not spend time on Internet and search for the information. 
Thus, respondents would react either positively or negatively to the particular advertisement that appears to them.

\subsubsection{Attitude toward Advertised Brand (Ab)}

Attitude toward advertised brand $(\mathrm{Ab})$ is defined as a tendency to reply in either a favourable or unfavourable manner towards the specific brand after the exposure of advertising on that person (Phelps \& Hoy, 1996).

According to Baker (2001), consumer's attitude toward advertised brand would change in three circumstances: (1) changes in the information environment - it depends on the accessibility of positive brand information and the time of advertising exposure; (2) changes in consumer's motivation, opportunity, or ability - consumer would have judgement on the brand at a first judgment occasion and based on global prior judgement; and (3) changes in the evaluation process - this involve when there are undergoing choice process. Therefore, the study of Jeon and Beatty (2002) indicates that different countries and ads type would have a significant impact on $\mathrm{Ab}$.

Advertisement plays an important role in building positive $\mathrm{Ab}$ because consumer would first get-in-touch with the advertisement, and then build up emotional feeling of favourable or unfavourable manner towards the advertised brand which leads to further purchase. With interactive ads, the motion graphics, sound, and animation would engage readers and create favourable Ab. Lee (1995) states that there is a significant influence between consumers' response and brand advertising. Furthermore, a positive Ab will not only lead to the brand itself, but also for future brand extension (Lee, 1995).

\subsubsection{Purchase Intention (PI)}

Purchase intention (PI) is referred to as the intention to either purchase or reject a product (Haugtvedi, Machleit $\&$ Yalch, 2005) and it is also one of the main criteria used to measure the effectiveness of advertising and to anticipate a consumer's response (Haugtvedi, Machleit \& Yalch, 2005).

Through the study that tested by using Adobe Content Viewer (static ads) and iPad (interactive ads), Wang (2011) discovers that the generation Y consumers are more likely to interact with the ad and obtain a higher purchase intention. Besides, the way how an advertisement being presented and on which type of website being used would effect on the consumer purchase intention (Olney et al., as cited in Yang, 1996; PWC, 2012). Furthermore, Grigorovici and Constantin (2004) mention that one's purchase intention will be different based on the type of product being advertised as well as one's involvement towards the product. In addition, Yang (1996) also argues that the purchase intention of the consumers may be much depended on their interests to shop virtual stores. Through the Yang (1996) study, the findings indicate that the conveniences, time saving, and innovativeness of online shopping would play a role in affecting consumer's purchase intention. Not only that, the environmental influences (e.g. culture, family, and social class), presence of alternative products, and individual differences (e.g. education, attitudes, and lifestyle) may as well play a part in affecting one's purchase intention.

\subsubsection{Time of Exposure to Advertisement}

Nowadays many advertising agencies measure consumer behaviour towards advertising by determining their time spend on the advertisement. The effectiveness of advertising can be evaluated based on the sizable of the audience that expose to the advertisement, the targeted audience segments and the audiences' knowledge and behaviour after the exposure of the advertisement (Yang, 1996).

Contrasting with traditional advertising, interactive advertising does not control over the exposure time and the frequency that consumer being exposed to the interactive advertisement. That is the reason why the firm has no idea whether the consumer has clicked on the advertisement, or was it has been seen by the same consumer for times (Yang, 1996). Thus, the time of exposure to advertisement is often being used to measure the advertising effectiveness by looking at how long a consumer spends looking at an advertisement, and the number of times the particular website being surfed during the period of advertising campaign (Olney et al., as cited in Yang, 1996; Lavrakas, 2010). Yang (1996) discovers that consumer spends more exposure time in viewing the non-interactive advertisements because consumer does not have much choice but to look at the advertisement at a controlled pace and shows a keen interest towards the products advertised.

\subsection{Conceptual Framework}

The conceptual framework for this research was developed based on the extant literature review in the area of the effectiveness of advertising and interactive advertising. 


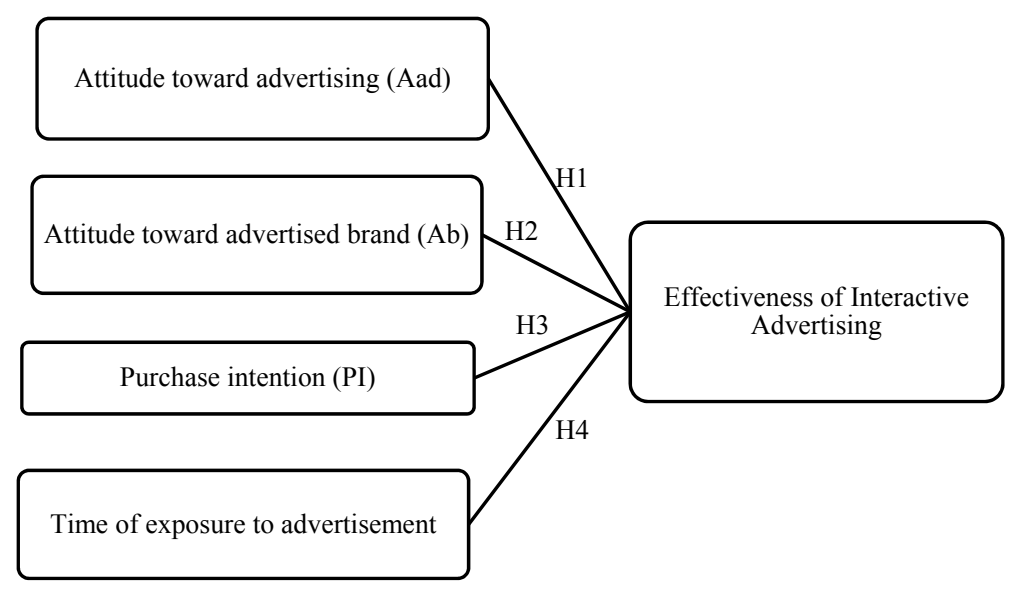

Figure 1. The proposed conceptual framework for this study

\subsection{Hypotheses}

Based on the proposed conceptual framework, four tested hypotheses are listed as follow:

H1: The attitude toward advertising is positively related to the effectiveness of interactive advertising.

$\mathrm{H} 2$ : The attitude toward advertised brand is positively related to the effectiveness of interactive advertising.

H3: The purchase intention is positively related to the effectiveness of interactive advertising.

H4: The time of exposure to advertisement is positively related to the effectiveness of interactive advertising.

\section{Research Methodology and Design}

\subsection{Research Design}

A research design is a blueprint to conduct a research project (Malhotra, 2010). Descriptive research is adopted in this research to test the hypothesized relationship (Malhotra, 2010). In order to meet the requirements of a conclusive research design, the data collection for this study will be based on survey method because this method could accommodate large sample size, the response rate is higher, and be able to reach the units specified in the sample effectively and efficiently (Malhotra, 2010). The study will be based on primary data collection and a cross-sectional study will be carried out.

\subsection{Questionnaire Design}

Questionnaire survey was adopted as a survey instrument in the study. The content of questionnaire is separated into two sections. The first section (Section A) is the basic demographic survey which consists of five questions of nominal and ordinal data in measuring respondent's profiling such as gender, age, nationality, education level, and monthly income.

The second section (Section B) of the questionnaire elaborates the tested constructs in the study. The items for the dependent variable ('effectiveness of interactive advertising') were adapted from Martin, Bhimy and Agee (2002). The items that measure the independent variable ('attitude towards the advertisement') were adopted from Friman (2010). Whereas, the items that measure the other independent variables ('attitude towards the advertised brand' and 'purchase intention') were gathered from Wu, Wei and Chen (2008). All the items that measure the above mentioned four tested constructs were evaluated by five -point likert scale, ranging from strongly disagree to strongly agree. In addition, items that measure the construct 'time of exposure to advertisements' were adapted from Fleming, Thorson and Atkin (2004) in which the tested items were evaluated by 5-point likert scale, ranging from one, just one, a few, some, to many. For the purpose of ensuring error free in designing the questionnaire, a pilot test was conducted among 30 university students with multimedia background by using convenience sampling. Based on the feedbacks received from the pilot test, the questionnaires were improved and finalised.

\subsection{Sampling and Administration of Survey}

In this study, the target for the respondents will be tertiary students (majoring in mass communication with multimedia background, batch January to April 2012) who study in one of the private universities in Kuala 
Lumpur, Malaysia. According to Han and Ocker (2002), there are various worthwhile to target university students: (1) Computer dependence - More than 90 percent of students are Internet user and among them 30 percent are computer dependent; (2) Computer access availability - in year 2012, almost all universities throughout Malaysia is provided with the Internet access (Minges \& Gray, 2002). The chances for them to access interactive advertising via social media are very high; and (3) Potential lifetime members and future money maker - companies often target tertiary students by providing discount hoping that when they graduate and build their career, they will still continuously using the brand by turning them to become lifetime and brand-loyal customers. On top of that, based on the survey of the Nielsen Company Malaysia in 2011, the statistic indicates that the highest Internet usage of age group in Malaysia is between the age group of 20-24. In Malaysia, it is estimated that about $25 \%$ of the total population with the age group of 18-24 is in higher education (Mukherje, 2010).

In this study, the non-probability sampling techniques were selected to conduct the survey, and in particularly by using convenience sampling. The reason for selecting non-probability sampling techniques is that the author could not manage to obtain the name list of all university students who major in mass communication (herein refer to sampling frame). As for the convenience sampling, it was chosen because: (1) the respondents (students) were presented at the venue on that particular time slot, before and after classes were conducted; and (2) they are qualified to be the target population. All of the respondents were requested to voluntary fill up the questionnaire based on their knowledge on multimedia, recent contact with the online advertisement and their attitude towards the interactive advertisement.

Malhotra (2010, p. 374) refers sample size as "the number of elements to be included in the study". A large sample size is required for such a descriptive survey. Yang $(1996 ; 1997)$ selects 108 respondents in his study to test the effectiveness of advertising. Malhotra (2010) suggests that sample size for the study of advertising, the minimum should be 150 and the typical range is around 200 to 300. Whereas, Sekaran (2003) suggests that sample size which are larger than 30 and less than 300 are normally applicable for most research, and recommends the sample size should be 10 times the number of variables in the study. Thus, the sample size that set for this research was 160 .

According to Siniscalco and Auriat (2005), the standardized questionnaires are often collected by asking people questions through interview and/or by self-administrated questionnaires. Self-administrated survey method was adopted in this survey. Since all of the respondents were accommodated with multimedia knowledge and background, the survey was conducted in the classroom and multimedia laboratories where respondents could return the questionnaire right after they have completed in answering the questionnaires. A cover page was included in the questionnaire and the ethical guidelines were informed to the respondents during the survey administration.

The total number of questionnaires distributed in the self-administrated survey was 160 sets. Based on the collected questionnaires, 3 sets of questionnaire were considered error and unusable because they were incomplete or have double answers and the other 8 sets of questionnaires were not returned. Assumption was made that the respondents were either reluctant to collaborate or did not want to answer the questionnaire seriously. As a result, only 149 valid sets of questionnaires (93.13\%) were left and then used for further analysis in this research by using SPSS software version 20. Descriptive analysis, scale measurement analysis and inferential analysis were carried in the data analysis for this research.

\section{Research Results}

\subsection{Respondents'Demographic Profiles}

Based on this survey, there were 44.3 percent of male respondents (66 male respondents) and 55.7 percent (83 female respondents) of the female respondents. The age distribution of the respondents between the age of 20-25 years old (61.1 percent) scored the highest respondent's age group, followed by between the age less than 20 years old (18.8 percent), age between 26-30 years old (12.8 percent), age between 31-25 years old (6 percent), age between $36-40$ years old ( 0.7 percent) and the lowest score of the respondent's age group is age more than 40 years old $(0.7$ percent).

\subsection{Reliability Test}

In the general rule of thumb, the value of Cronbach's alpha of more than 0.70 is considered acceptable and good while measure the reliability of the items within the construct (Cavana et al., 2001), and this value will be used to ensure the stability and consistency for the adopted instruments. 
Table 1 . Reliability test of variables

\begin{tabular}{ll}
\hline Variables & Composite Reliability \\
\hline Attitude toward Advertising & 0.824 \\
Attitude toward Advertised Brand & 0.865 \\
Purchase Intention & 0.884 \\
Time of Exposure to Advertisement & 0.864 \\
Effectiveness of Interactive Advertising & 0.845 \\
\hline
\end{tabular}

According to the result of reliability test that was shown in Table 1, the Cronbach's Alpha value for the constructs ranged from the lowest of 0.824 to 0.884 . As a conclusion, the results has shown that all constructs used in this research had exceeded the preferable scores of 0.70 and this means that the measurements scales of the constructs were stable and consistent in measuring the constructs (Cavana et al., 2001).

\subsection{Validity Test}

Exploratory factor analysis was carried out in this research to verify the validity of the tested constructs in the conceptual framework (Cavana et al., 2001). The details of the factor analysis can be found in Table 2. From the output, it has shown that the factor analysis was appropriate because the value of Kaiser-Meyer-Olkin (KMO) was 0.848 (between 0.5 and 1.0) and the statistical test for Bartlett test of sphericity was significant ( $\mathrm{p}=0.000$; d.f. $=120$ ) for all the correlations within a correlation matrix (at least for some of the constructs). Based on the principal components analysis and VARIMAX procedure in orthogonal rotation, the results also showed that the Eigenvalues for all the constructs were greater than 1.0, ranging from the lowest 1.019 (Attitude toward Advertised Brand) to the highest of 6.142 (Effectiveness of Interactive Advertising). In terms of convergent validity, the factor loadings for all the items within a construct were more than 0.50 . Discriminant validity indicated that all items were allocated according to the different constructs. Therefore, the items were not overlapping and they supported the respective constructs.

Table 2. Factors identified by the principal components factor analysis

\begin{tabular}{|c|c|c|c|c|c|}
\hline Factor's Name & Variable & $\begin{array}{l}\text { Factor } \\
\text { Loading }\end{array}$ & $\begin{array}{l}\text { Eigen- } \\
\text { value }\end{array}$ & $\begin{array}{l}\text { Percentage } \\
\text { of Variance } \\
\text { Explained }\end{array}$ & $\begin{array}{l}\text { Cronbach's } \\
\text { Reliability } \\
\text { Coefficients }\end{array}$ \\
\hline \multirow{3}{*}{$\begin{array}{l}\text { Attitude toward } \\
\text { Advertising } \\
\text { (Aad) }\end{array}$} & I like online advertising. & 0.759 & 1.767 & 15.543 & 0.824 \\
\hline & $\begin{array}{l}\text { Online advertising helps me keep up-to-date about products and services } \\
\text { that I am interested in. }\end{array}$ & 0.802 & & & \\
\hline & Online advertising is disturbing [R]. & 0.759 & & & \\
\hline \multirow{3}{*}{$\begin{array}{l}\text { Attitude toward } \\
\text { Advertised } \\
\text { Brand }(\mathrm{Ab})\end{array}$} & $\begin{array}{l}\text { After viewing online advertisements, I am more in love with the advertised } \\
\text { brand. }\end{array}$ & 0.800 & 1.019 & 15.185 & 0.865 \\
\hline & $\begin{array}{l}\text { After viewing online advertisement, I developed preference for the brand in } \\
\text { the advertisement. }\end{array}$ & 0.787 & & & \\
\hline & $\begin{array}{l}\text { After viewing online advertisement, my impression for the product brand is } \\
\text { strengthened. }\end{array}$ & 0.885 & & & \\
\hline \multirow[t]{2}{*}{$\begin{array}{l}\text { Purchase } \\
\text { Intention }\end{array}$} & $\begin{array}{l}\text { After viewing the online advertisement, I am willing to try using the } \\
\text { product. }\end{array}$ & $\begin{array}{l}0.873 \\
0.789\end{array}$ & 2.363 & 15.648 & 0.884 \\
\hline & $\begin{array}{l}\text { After viewing the online advertisement, I become interested in making a } \\
\text { purchase. } \\
\text { After viewing the online advertisement, I will purchase the brand being } \\
\text { advertised. }\end{array}$ & 0.854 & & & \\
\hline \multirow{2}{*}{$\begin{array}{l}\text { Time of } \\
\text { Exposure to } \\
\text { Advertisement }\end{array}$} & $\begin{array}{l}\text { In a typical week, about how many banner(s) appeared in the online } \\
\text { advertisement do you see? }\end{array}$ & 0.853 & 1.173 & 15.336 & 0.864 \\
\hline & $\begin{array}{l}\text { In a typical week, about how many online advertisements do you see? } \\
\text { About how many commercial advertisements appeared in online do you } \\
\text { see in a typical week? }\end{array}$ & 0.883 & & & \\
\hline \multirow{4}{*}{$\begin{array}{l}\text { Effectiveness of } \\
\text { Interactive } \\
\text { Advertising }\end{array}$} & I found that online advertising is interesting and informative. & 0.716 & 6.142 & 16.181 & 0.845 \\
\hline & I found that online advertising is entertaining and fun to watch. & 0.761 & & & \\
\hline & I could relate to the people in the advertisement who tried the product. & 0.728 & & & \\
\hline & $\begin{array}{l}\text { The host or celebrity in the advertisement made me feel the product was a } \\
\text { good one. }\end{array}$ & 0.809 & & & \\
\hline
\end{tabular}

Notes: KMO Measure of Sampling Adequacy $=0.848 ; \mathrm{p}=0.000(\mathrm{p}<0.05) ; \mathrm{df}=120$; Cumulative Percentage Rotation Sums of Squared Loadings $=77.894$. 


\subsection{Inferential Analysis}

\subsubsection{Multiple Regression Analysis}

The outcome of the multiple regression analysis for all the four hypotheses was presented in Table 3 as below. In related to the first hypothesis (H1), the $p$ value of the 'attitude towards advertisement' $(p=0.000)$ is less than the alpha value of 0.05 . The value of unstandardized beta coefficient is 0.542 . Thus, it shows that there is a positive relationship between 'attitude towards advertisement' and the 'effectiveness of interactive advertisement'. Therefore, hypothesis 1 is supported.

The result of the multiple regression analysis for the hypothesis 2 , the $\mathrm{p}$ value of the 'attitude towards advertised brand' $(\mathrm{p}=0.158)$ is more than the alpha value of 0.05 . The value of unstandardized beta coefficient is 0.149 . Thus, it shows that there is no relationship between 'attitude towards advertised brand' and the 'effectiveness of interactive advertising'. Thus, hypothesis 2 is failed to be accepted.

The result of the multiple regression analysis for the hypothesis 3 , the $\mathrm{p}$ value of the 'purchase intention' $(p=0.046)$ is less than the alpha value of 0.05 . The value of unstandardized beta coefficient is 0.200 . Thus, it shows that there is a positive relationship between 'purchase intention' and the 'effectiveness of interactive advertising'. Thus, hypothesis 3 is supported.

The result of the multiple regression analysis for the hypothesis 4 , the p value of the 'time of exposure to advertisement' $(p=0.888)$ is more than the alpha value of 0.05 . The value of unstandardized beta coefficient is 0.010 . Thus, it shows that there is no relationship between 'time of exposure to advertisement' and the 'effectiveness of interactive advertising'. Thus, hypothesis 4 is failed to be accepted.

Table 3. The statistical output of multiple regression analysis for this research

\begin{tabular}{llll}
\hline Variables & Unstandardized Beta Coefficients & t-value & Significant \\
\hline Attitude towards advertisement (H1) & 0.542 & 4.512 & 0.000 \\
Attitude towards advertised brand (H2) & 0.149 & 1.420 & 0.158 \\
Purchase Intention (H3) & 0.200 & 2.008 & 0.046 \\
Time of Exposure to advertisement (H4) & 0.010 & 0.141 & 0.888 \\
\hline
\end{tabular}

Notes: Dependent variable: Effectiveness of Interactive Advertising; $\mathrm{R}=61.7$ per cent; $\mathrm{R}$ Square $=38.1$ per cent; Adjusted $\mathrm{R}$ Square $=36.4$ per cent; $\mathrm{F}=22.308 ; \mathrm{P}=0.0001(\mathrm{p}<0.05)$; Unstandardized Coefficient for Constant $=5.275$.

As a conclusion, the values of unstandardized beta coefficient among the significant independent variables tested in the hypotheses ranged from the weakest relationship of 0.200 (between 'purchase intention' and 'effectiveness of interactive advertising') to the strongest relationship of 0.542 (between 'attitude towards advertisement' and 'effectiveness of interactive advertising'). It shows that attitude towards advertisement is the most powerful factor in affecting the effectiveness of interactive advertising.

\section{Conclusion}

\subsection{Implications of the Research}

The research outcomes and contributions have created theoretical and managerial implications to the various interested party.

From the theoretical perspective, firstly, the study has generated an empirical study for the effectiveness of interactive advertising. Secondly, the outcome of the results indicates that a positive relationship occurs between the attitude towards advertisement and purchase intention to the effectiveness of interactive advertising.

As for the managerial implication, the research outcomes could provide some understandings and opinions for the advertisers and companies on the measurement that they can consider when placing an interactive advertising. As the main objective for advertising is to increase the sales volume and brand image of a product or company, they should be aware of the attitude of consumer towards the interactive advertising and how would it affect the purchase intention.

\subsection{Limitations of the Research}

Even though the research outcomes provide some understandings to the researcher, these outcomes should be viewed with some limitations. The study's sample only consist of university students in Malaysia by using convenience sampling. Hence, the results from the study could not be generalized. Besides, the study concentrated on those respondents who have a background on mass communication with multimedia study, online experience and in-touch with online advertising before. As a result, the scope does not include those 
potential respondents who do not have any online experience but yet have positive attitudes towards the online advertising.

\subsection{Recommendations for Further Research}

With the limitations of this research, several recommendations are proposed for further research on the effectiveness of interactive advertising. The further research may consider to use probability sampling technique and adopt a wider representation of target group such as IT professionals, marketers and advertisers. The study has included four factors to evaluate the effectiveness of interactive advertising in the contact of social media. On top of the measure that tested, future research could add-on other influential factors on the advertising effects, such as click-on, reach and frequency in the study.

\section{References}

Baker, W. E. (2001). The diagnosticity of advertising generated brand attitudes in brand choice contexts. Journal of Consumer Psychology, 11(2), 129-139. http://dx.doi.org/10.1207/S15327663JCP1102_05

Brown, M., \& Logic, D. (2008). IAB research case study on digital video advertising effectiveness. Retrieved from http://www.iab.net

Cavana, R. Y. M., Delahaye, B. L., \& Sekaran, U. (2001). Applied business research: Aualitative and quantitative methods. Queensland: John Wiley \& Sons.

Chitty, W., Barker, N., Valos, M., \& Shimp, T. A. (2011). Integrated marketing communications (3rd Asia Pacific ed.). Canada: Cengage Learning.

Digital Direction. (2011). Interactive advertising - An overview. Retrieved from http://ddrxn.com

Dreze, X., \& Zufryden, F. (1998). Is Internet advertising ready for prime time? Marshall School of Business of the University of Southern California.

Duncan, T. (2005). IMC in industry: More talk than walk. Journal of Advertising, 34(4), 5-9.

Ferle, C. L., \& Lee, W. N. (2008). Attitudes toward advertising. Journal of International Consumer Marketing, 15(2), 5-3. http://dx.doi.org/10.1300/J046v15n02_02

Fleming, K., Thorson, E., \& Atkin, C. K. (2004). Alcohol advertising exposure and perceptions: Links with alcohol expectancies and intentions to drink or drinking in underaged youth and young adults. Journal of Health Communication, 9, 3-29. http://dx.doi.org/10.1080/10810730490271665

Friman, J. (2010). Consumer attitudes toward mobile advertising. School of Economics, Aalto University, Findland.

Grigorovici, D. M., \& Constantin, C. D. (2004). Experiencing interactive advertising beyond rich media: Impacts of ad type and presence on brand effectiveness in 3D gaming immersive virtual environments. Journal of Interactive Advertising, 5(1), 22-36.

Han, H. J., \& Ocker, R. J. (2002). Is it worthwhile to target university students? Decision Line, 3, 18-20.

Haugtvedi, C. P., Machleit, K. A., \& Yalch, R. F. (2005). Online consumer psychology: Understanding and influencing consumer behaviour in the virtual world. New Jersey: Lawrence Erlbaum Associates, Inc.

Hwang, J., Yoon, Y. S., \& Park, N. Y. (2011). Structural effects of cognitive and affective responses to web advertisements, website and brand attitudes, and purchase intentions: The case of casual-dining restaurants. $\begin{array}{llll}\text { International Journal of Hospitality } & \text { Management, } & 30(4), & \text { 897-907. }\end{array}$ http://dx.doi.org/10.1016/j.ijhm.2011.01.011

IAB. (2009). Internet advertising revenues surpass $\$ 23$ billion in '08 reaching record high. Retrieved from http://www.iab.net

IAB. (2012). IAB analysis shows digital media are vital influence on consumer electronics purchases. Retrieved from http://www.iab.net

IAB. (n.d.). Glossary of interactive advertising terms v. 2.0. Retrieved from www.iab.net

Jeon, J. O., \& Beatty, S. E. (2002). Comparative advertising effectiveness in different national cultures. Journal of Business Research, 55, 907-913. http://dx.doi.org/10.1016/S0148-2963(01)00210-7

Karimova, G. Z. (2011). 'Interactivity' and advertising communication. Journal of Media and Communication Studies, 3(5), 160-169.

Kitchen, P. J., \& Burgmann, I. (2010). Integrated marketing communication. Wiley International Encyclopedia 
of Marketing.

Kitchen, P. J., \& Pelsmacker, P. D. (2004). Integrated marketing communications: A primer. New York: Routledge.

Kitchen, P. J., Brignell, J., Li, T., \& Jones, G. S. (2004). The emergence of IMC: A theoretical perspective. Journal of Advertising Research, 44(1), 19-30. http://dx.doi.org/10.1017/S0021849904040048

Kliatchko, J. (2005). Towards a new definition of Integrated Marketing Communications (IMC). International Journal of Advertising, 24(1), 7-34.

Kotler, P., \& Keller, K. L. (2006). Marketing management (12th ed.). New Delhi: Prentice Hall.

Lavrakas, P. J. (2010). An evaluation of methods used to assess the effectiveness of advertising on the internet. New York: Interactive Advertising Bureau.

Lee, J. S. (1995). Role of attitude toward brand advertising on consumer perception of a brand extension. Advances in Consumer Research, 22, 116-122.

Li, H. (2011). The interactive web. Journal of Advertising Research. http://dx.doi.org/10.2501/JAR-51-1-013-026

Li, H., \& Leckenby, J. D. (2004). Internet advertising formats and effectiveness. Retrieved from $\mathrm{http} / / /$ brosephstalin.files.wordpress.com/2010/06/ad_format_print.pdf

Liu, Y. (2003). Developing a scale to measure the interactivity of web sites. Journal of Advertising Research, 43(2), 207-216.

Liu, Y., \& Shrum, L. J. (2002). What is interactivity and it is always such a good thing? Implications of definition, person, and situation for the influence of interactivity on advertising effectiveness. Journal of Advertising, 31(4), 53-64.

MacKenzie, S. B., \& Lutz, R. J. (1989). An empirical examination of the structural antecedents of attitude toward the ad in an advertising pretesting context. The Journal of Marketing, 53(2), 48-65. http://dx.doi.org/10.2307/1251413

Malhotra, N. K. (2010). Marketing research: An applied orientations (6th ed.). New Jersey: Prentice Hall.

Martin, B. A. S., Bhimy, A. C., \& Agee, T. (2002). Infomercials and advertising effectiveness: An empirical study. Journal of Consumer Marketing, 19(6), 468-480. http://dx.doi.org/10.1108/07363760210444850

Methan, A., \& Purvis, S. C. (1995). When attitudes towards advertising in general influence advertising success. Norfolk: Conference of The American Academy of Advertising.

Minges, M., \& Gray, V. (2002). Multimedia Malaysia: Internet case study. Retrieved from www.itu.int

Mukherjee, H. (2010). Access to and equity in higher education - Malaysia. Retrieved from www.worldbank.org

Pavlou, P. A., \& Stewart, D. W. (2000). Measuring the effects and effectiveness of interactive advertising: A research agenda. Journal of Interactive Advertising, 1(1), 62-78.

Peltier, J. W., Schibrowsky, J. A., \& Schultz, D. E. (2003). Interactive integrated marketing communication: Combining the power of IMC, the new media and database marketing. International Journal of Advertising, $22,93-115$.

Petley, J. (2002). Advertising. London: Hodder Wayland.

Phelps, J. E., \& Hoy, M. G. (1996). The Aad-Ab-PI relationship in children: The impact of brand familiarity and measurement timing. Psychology and Marketing, 13(1), 77-105. http://dx.doi.org/10.1002/(SICI)1520-6793(199601)13:1<77::AID-MAR5>3.0.CO;2-M

PWC. (2012). Measuring the effectiveness of online advertising. Study conducted by PwC for IAB France and the SRI. Retrieved from http://www.pwc.com

Saadeghvaziri, F., \& Seyedjavadain, S. (2011). Attitude toward advertising: Mobile advertising VS advertising-in-general. European Journal of Economics, Finance and Administrative Sciences, 28.

Sekaran, U. (2003). Research methods for business: A skill-building approach. New York: John Wiley \& Son.

Shimp, T. A. (2010). Advertising, promotion, and other aspects of integrated marketing communications. Canada: Cengage Learning.

Shrum, L. J., Lowrey, T. M., \& Liu, Y. (2009). Emerging issues in advertising research. In R. Nabi (Ed.), The 
SAGE Handbook of Media Processes and Effects (pp. 299-312). Thousand Oaks, CA: Sage Publications.

Siniscalco, M. T., \& Auriat, N. (2005). Questionnaire Design. Paris: International Institute for Educational Planning/ UNESCO.

Stanaland, A. J. S., Webster, L. B., \& Taylor, R. L. (2009). Direct and interactive marketing in IMC education: Marketing vs. mass communication approaches. International Journal of Integrated Marketing Communications, Spring, 74-85.

The Nielson Company. (2009). Online advertising effectiveness. Retrieved from www.nielsen-online.com

Thorson, E., \& Moore, J. (1996). Integrated communication: Synergy of persuasive voices. New Jersey: Lawrence Erlbaum Associates, Inc.

Wang, A. (2011). Digital ad engagement: Perceived interactivity as a driver of advertising effectiveness. Retrieved from www.adobe.com

Wu, S. I., Wei, P. L., \& Chen, J. H. (2008). Influential factors and relational structure of Internet banner advertising in the tourism industry. Tourism Management, 29, 221-236. http://dx.doi.org/10.1016/j.tourman.2007.03.020

Yang, C. C. (1996). Interactive advertising and its effectiveness: An exploratory study. Advertising Research, 8 , 27-65.

Yang, C. C. (1997). An exploratory study of the effectiveness of interactive advertisements on the internet. Journal of Marketing Communications, 3(2), 61-85. http://dx.doi.org/10.1080/135272697345970

Yoo, C. Y., Kim, K., \& Stout, P. A. (2004). Assessing the effects of animation in online banner advertising: Hierarchy of effects model. Journal of Interactive Advertising, 4(2), 49-60. 